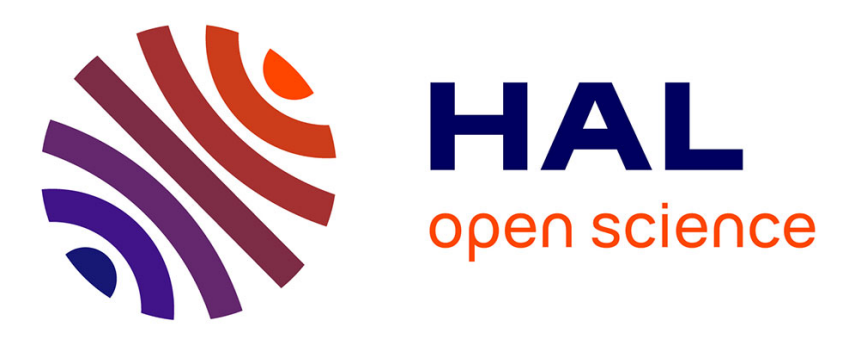

\title{
Low Altitude Thermal Survey by Means of an Automated Unmanned Aerial Vehicle for the Detection of Archaeological Buried Structures
}

Nicolas Poirier, Florent Hautefeuille, Carine Calastrenc

\section{- To cite this version:}

Nicolas Poirier, Florent Hautefeuille, Carine Calastrenc. Low Altitude Thermal Survey by Means of an Automated Unmanned Aerial Vehicle for the Detection of Archaeological Buried Structures. Archaeological Prospection, 2013, 20 (4), pp.303-307. 10.1002/arp.1454 . hal-00844459

\author{
HAL Id: hal-00844459 \\ https://hal.science/hal-00844459
}

Submitted on 14 Jan 2015

HAL is a multi-disciplinary open access archive for the deposit and dissemination of scientific research documents, whether they are published or not. The documents may come from teaching and research institutions in France or abroad, or from public or private research centers.
L'archive ouverte pluridisciplinaire $\mathbf{H A L}$, est destinée au dépôt et à la diffusion de documents scientifiques de niveau recherche, publiés ou non, émanant des établissements d'enseignement et de recherche français ou étrangers, des laboratoires publics ou privés. 


\title{
Low altitude thermal survey by means of an automated UAV for the detection of archaeological buried structures.
}

\author{
Nicolas Poirier, Florent Hautefeuille, Carine Calastrenc \\ UMR 5608 TRACES, CNRS - Université Toulouse 2 - Le Mirail \\ Université Toulouse 2 - Le Mirail, Maison de la Recherche, UMR 5608 TRACES, 5 Allée Antonio \\ Machado, FR-31058 Toulouse cedex 9, nicolas.poirier1@univ-tlse2.fr, +33561502350
}

\begin{abstract}
Airborne thermal prospecting is based on the principle that there is a fundamental difference between the thermal characteristics of buried remains from the environment in which they are buried. The French 'Archéodrone' project aims to combine the flexibility and low cost of using an airborne drone with the accuracy of the registration of a thermal digital camera. This combination allows the use of thermal prospection for archaeological detection at low altitude with high-resolution information, from a microregional scale to the site scale. The first results have already allowed us to assess the contribution of this technique for the detection of ancient roads, parcel boundaries, site plans and underground caves.
\end{abstract}

Keywords : UAV, thermal survey, site detection, mapping, aerial archaeology, remote sensing

\section{State of the art and objectives}

Richard Atkinson is usually considered as the first who developed, for the first time in 1946, a ground-based non-invasive method to get a detailed map of the archaeological site by the study of the electrical resistivity of soil (Atkinson, 1946); although earlier experiments have been documented (Bevan 2000) It was followed by the development of techniques such as, magnetic mapping and Ground Penetrating Radar. The development of air and space-based techniques, such as multispectral satellite remote-sensing or Airborne Laser Scanning, has diversified the methods and thus increased the number of tools to visualize archaeological remains without direct intervention (Devereux et al., 2005; Bewley et al., 2005; Lasaponara et al., 2010).

Airborne thermal prospecting is one of these non-invasive methods. It is based on the principle that there is a fundamental difference between the thermal characteristics of buried remains 
from the environment in which they are buried (Eppelbaum, 2009). Therefore archaeological structures tend to react differently to changes in temperature compared to the surrounding sediment (warming or cooling more or less quickly depending on their nature). For example, structures built of stone and mortar present a greater thermal inertia than the surrounding sediment; conversely, hollow structures (ditches and pits) have a lower thermal inertia, allowing their detection on bare soils (Rowlands and Sarris, 2007). On cultivated soils, the hydric stress of cereals disturbs their thermal regulation, permitting the detection of remains before they are visible on conventional pictures as crop marks (Aqdus et al., 2012) as visible on figure 3 for example.

This detection method has been used in archeology since the 1970s (Bellerby et al., 1990; BenDor et al., 2001; Berlin et al., 1977; Lundén, 1985; Prakash et al., 1995; Tabbagh, 1977). But the use of aircraft or satellite imagery made the method difficult to access due to its cost and lack of organizational flexibility: flights must be scheduled several weeks in advance and the relatively high flight altitude is only able to detect large structures (abandoned roads and parcel boundaries).

The parallel development of Unmanned Aerial Vehicles (UAV) and miniaturization of sensors and data transmission suggests a technological breakthrough in terms of archaeological prospection (Bendea et al., 2007; Chiabrando et al., 2011; Eisenbeiss \& Zhang, 2006; Eisenbeiss et al., 2005; Everaerts, 2008; Hendrickx et al., 2011; Verhoeven, 2009). However, the recent development of UAVs has so far benefited archaeological survey by the addition of conventional digital cameras, to achieve vertical or oblique aerial photographs, mainly at the scale of a site or excavation.

The French 'Archéodrone' project, developed at the University of Toulouse 2 - Le Mirail (France), aims to combine the flexibility and relative low cost of using an airborne drone with the accuracy of the registration of a thermal digital camera. Indeed, even if the price of acquiring the equipment is quite high (several dozens of thousand Euros), the possibility to repeat as many flights as needed makes the methodology affordable compared to the price of a single plane or helicopter flight. This combination allows the use of thermal survey for archaeological detection at low altitude, resulting in a higher resolution of information, from a micro-regional scale to the site scale, and the possibility to repeat several flights above the same area in different air and soil conditions.

\section{Equipment used}

The UAV used is an octoroctor helicopter (Figure 1) with electric propulsion and a wingspan of about $80 \mathrm{~cm}$, with a three-dimensional inertial stabilization system and a GPS for its geolocation. It is radio controlled and allows a payload of $3 \mathrm{~kg}$. It is accompanied by a telemetry system to display real-time flight data: battery consumption, flight time, altitude, distance from the point of takeoff, and GPS status. The same system is used to display a map and manage the GPS' points of interest (waypoints). 
The sensor used is a FLIR T620 thermal digital camera with high sensitivity for the detection of temperature changes of about $0.04{ }^{\circ} \mathrm{C}$, on images of $640 \times 480$ pixels. A radio transmission system captures the camera images in real-time and can track the flight on a LCD screen with return video.

The whole equipment was acquired for about 70,000 €. This is a large investment for a research team, but we consider this as a low cost method given that this material will be usable for several years, several times a day and several days in a row if needed during a survey campaign. This should be compared to expensive "one-shot" data acquisition such as airborne Lidar or thermography.

\section{Intervention process}

The intervention process first consists in the definition of flight plans ahead of field data acquisition. For this, the Mikrokopter Tool software allows extraction of geographical views at the plot scale from web portals like Google Earth or Virtual Earth. It is then possible to generate flight plans by creating waypoints to be followed by the UAV in automated flight mode guided by GPS. These waypoints can be automatically generated, including regular grids which the operator defines the equidistance and altitude. This option is particularly useful when it comes to cover an entire plot of land (Figure 2).

In the field, the operator can choose to perform manual takeoff and landing operations, while the flight itself can be automated following the waypoints through GPS guidance. When the UAV is stopped on each waypoint, the operator starts data capture, controlling in real-time quality and recording thanks to the return video system.

\section{Post-processing and first results}

In the laboratory, the captured images can be processed to improve the recognition of thermal anomalies (stretching and compression of the histogram of the measured values, application of different ranges of colors, etc). It is possible to restrict the range of representation of the color composition to reduced amplitude of a single degree Celsius, using the FLIR Tools software.

The calibration process of the intervention protocol is still in progress, but the first results have already allowed us to assess the contribution of this technique for the detection of ancient roads and parcel boundaries (Figure 3). But the experiment in progress promises a high potential for detection at the site level of smaller structures, thanks to the low altitude of the flights. For example, the first tests performed over the ancient roman town of Saint-Bertrandde-Comminges (South of France) revealed evidence of correlation between ancient urban plans (streets network, buildings) and linear thermal anomalies (Figure 4).

The potential is also important regarding the detection of underground cavities whose presence is manifested on the surface by different temperature from that of the atmosphere and the surface of the soil. We already experienced this detection process of underground 
cavities on the two prehistoric sites of Kroomdraï and Sterkfontein in the south-African Cradle of Humankind (Figure 5).

The coupling of the thermal camera and the drone is still new. Ongoing tests aim to define an intervention protocol to determine what is the optimal flight altitude, time, and ground cover for the detection of buried remains based on a small corpus of sites periodically overflown in various flight conditions. The flexibility of the machine makes it possible to take the decision to fly on the day, and repeat it several times a day over the same plot if necessary. It is already obvious that the low altitude of flights permits a gain in resolution to detect archaeological buried remains.

\section{Acknowledgements}

The purchase of the equipment was funded by the European Union through the FEDER Presage 35827 project.

\section{References}

Aqdus S.A., Hanson W.S. \& Drummond J. 2012. The potential of hyperspectral and multispectral imagery to enhance archaeological cropmark detection: a comparative study. Journal of Archaeological Science 39(7): 1915-1924.

Atkinson R.J.C. 1946. Field Archaeology. Methuen: London.

Bellerby T.J., Noel M. \& Branigan K. 1990. A Thermal Method for Archaeological Prospection: Preliminary Investigations. Archaeometry 32(2): 191-203.

Bendea A., Chiabrando F., Giulio Tonolo F., et al. 2007. Mapping of archaeological areas using a low-cost UAV. The Augusta Bagiennorum test site. In XXI International CIPA Symposium, 01-06 octobre 2007, Athens, Greece, XXI International CIPA Symposium. Athens, Greece. Available at: http://www.isprs.org/proceedings/XXXVI/5C53/papers/FP025.pdf.

Ben-Dor E., Kochavi M., Vinizki L., et al. 2001. Detection of buried ancient walls using airborne thermal video radiometry. International Journal of Remote Sensing 22(18): 3689-3702.

Berlin G.L., Ambler J.R., Hevly R.H., et al. 1977. Identification of a Sinagua Agricultural Field by Aerial Thermography, Soil Chemistry, Pollen/Plant Analysis, and Archaeology. American Antiquity 42(4): 588-600.

Bevan B. W. 2000. An early geophysical survey at Williamsburg, USA. Archaeological Prospection 7: 51-58.

Bewley R.H., Crutchley S.P. \& Shell C.A. 2005. New light on an ancient landscape: lidar survey in the Stonehenge World Heritage Site. Antiquity 79: 636-648. 
Chiabrando F., Nex F., Piatti D., et al. 2011. UAV and RPV systems for photogrammetric surveys in archaelogical areas: two tests in the Piedmont region (Italy). Journal of Archaeological Science 38(3): 697-710.

Devereux B.J., Crow G.S., Amable P., et al. 2005. The potential of airborne lidar for detection of archaeological features under woodland canopies. Antiquity 79(February): 648-660.

Eisenbeiss H., Lambers K., Sauerbier M., et al. 2005. Photogrammetric documentation of an archaeological site (Palpa, Peru) using an autonomous model helicopter. In CIPA 2005 XX International Symposium, 26 September - 01 October, 2005, Torino, Italy, Available at: http://www.photogrammetrie.ethz.ch/research/pinchango/238.pdf.

Eisenbeiss H. \& Zhang L. 2006. Comparison of DSMs generated from mini UAV imagery and terrestrial laser scanner in a cultural heritage application. In ISPRS commission $V$ Symposium "Image Engineering and Vision Metrology", IAPRS: Dresden; 90-96. Available at: http://www.isprs.org/proceedings/XXXVI/part5/paper/EISE_649.pdf.

Eppelbaum L. 2009. Near-surface temperature survey: An independent tool for delineation of buried archaeological targets. Journal of Cultural Heritage 10, Supplement 1: e93e103.

Everaerts J. 2008. The use of unmanned aerial vehicles (UAVs) for remote sensing and mapping. In The International Archives of the Photogrammetry, Remote Sensing and Spatial Information Sciences. Vol. XXXVII. Part B1. Beijing 2008, The International Archives of the Photogrammetry, Remote Sensing and Spatial Information Sciences. Vol. XXXVII. Part B1. Beijing 2008. Beijing; 1187-1192. Available at: http://www.isprs.org/proceedings/XXXVII/congress/1_pdf/203.pdf.

Hendrickx M., Gheyle W., Bonne J., et al. 2011. The use of stereoscopic images taken from a microdrone for the documentation of heritage - An example from the Tuekta burial mounds in the Russian Altay. Journal of Archaeological Science 38(11): 2968-2978.

Lasaponara R., Coluzzi R., Gizzi F.T., et al. 2010. On the LiDAR contribution for the archaeological and geomorphological study of a deserted medieval village in Southern Italy. Journal of Geophysics and Engineering 7(2): 155-163.

Lundén B. 1985. Aerial Thermography: A Remote Sensing Technique Applied to Detection of Buried Archaeological Remains at a Site in Dalecarlia, Sweden. Geografiska Annaler. Series A, Physical Geography 67(1/2): 161-166.

Prakash A., Sastry R.G.S., Gupta R.P., et al. 1995. Estimating the depth of buried hot features from thermal IR remote sensing data: a conceptual approach. International Journal of Remote Sensing 16: 2503-2510.

Tabbagh A. 1977. II Prospections thermiques et électriques. Gallia préhistoire 20(1): 271-280.

Verhoeven G.J.J. 2009. Providing an archaeological bird's-eye view - an overall picture of ground-based means to execute low-altitude aerial photography (LAAP) in Archaeology. Archaeological Prospection 16(4): 233-249. 


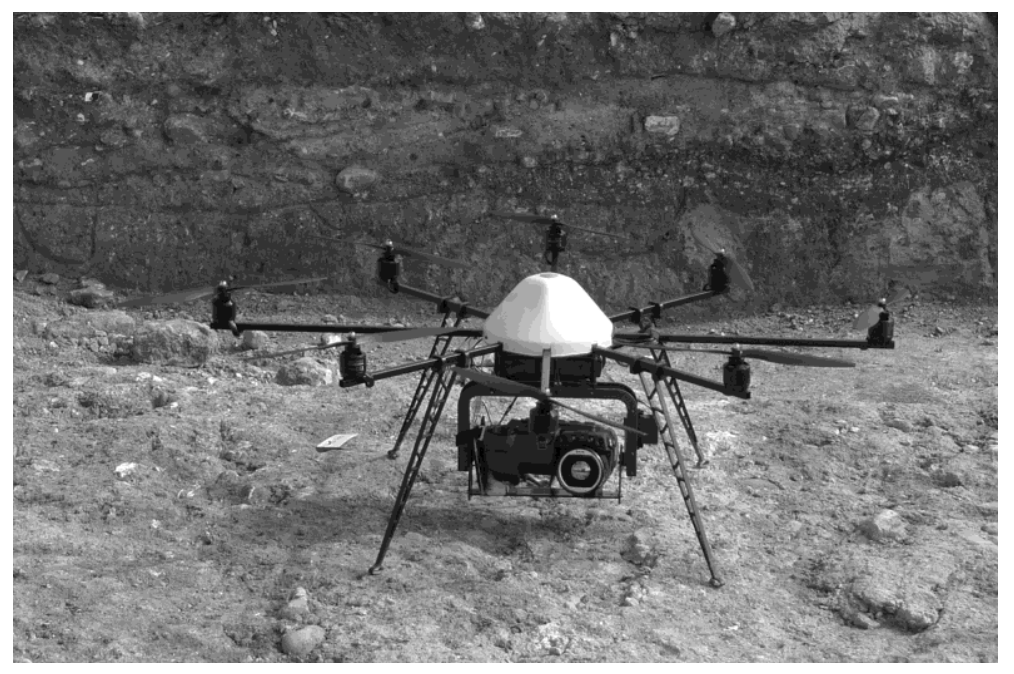

Figure 1 : Drone Octorotor with FLIR T620 thermal camera onboard

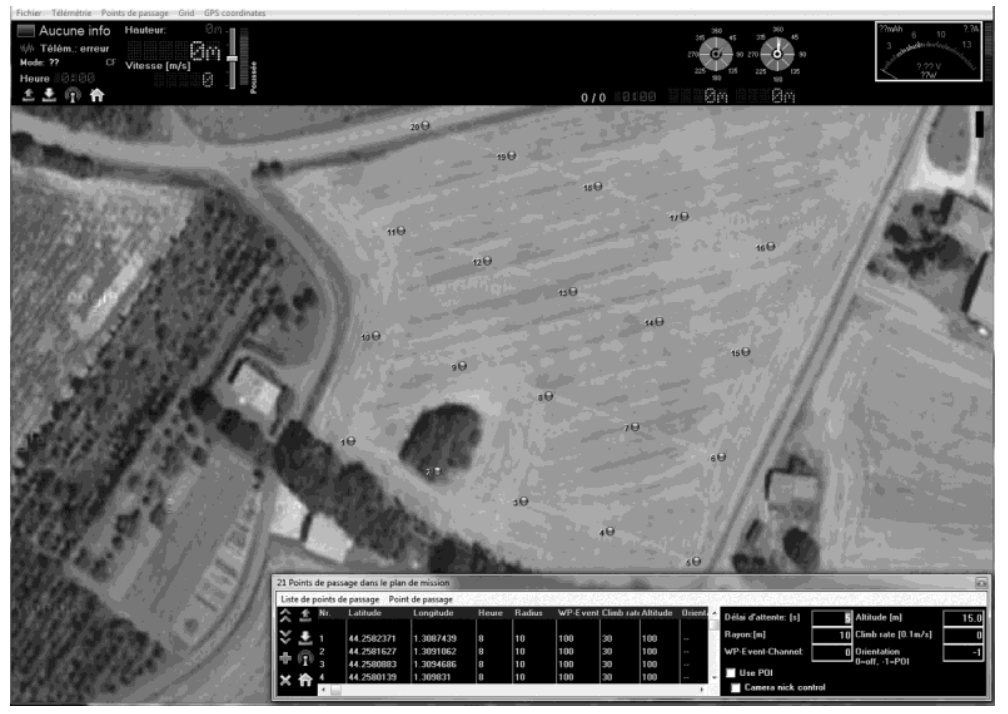

Figure 2 : Definition of a flight plan by equidistant waypoints automatically generated at a plot scale
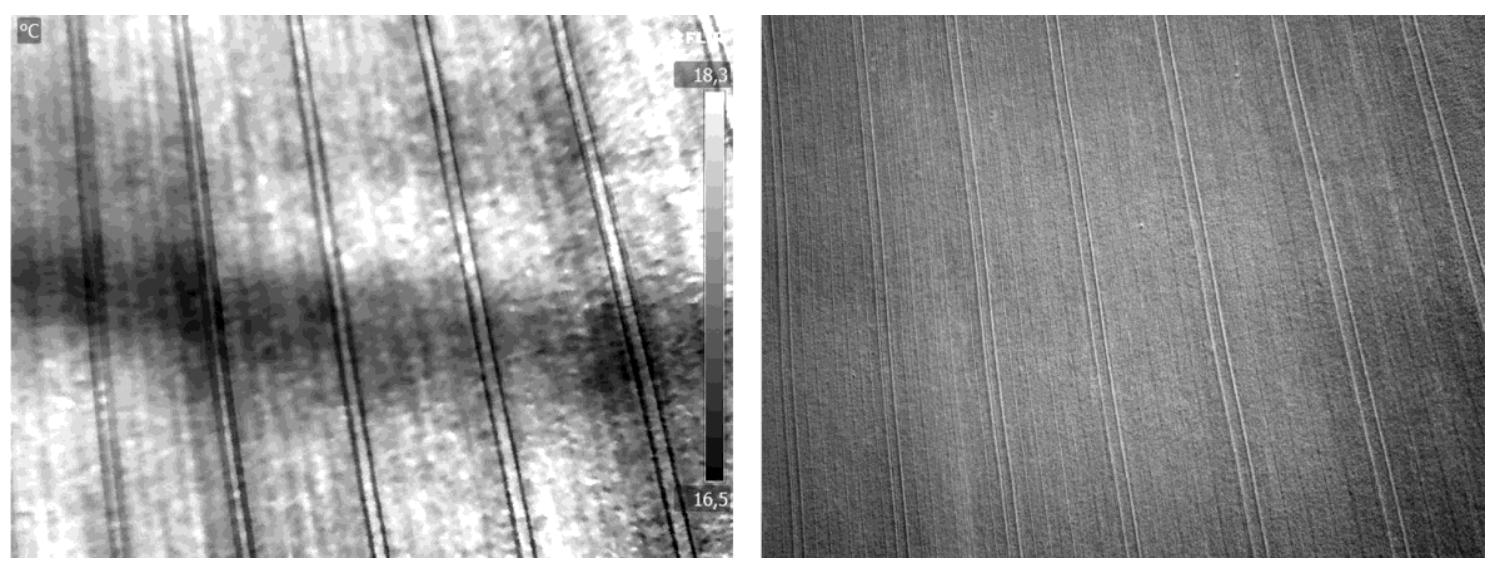
Figure 3 : On the left hand, the thermal image taken $100 \mathrm{~m}$ above the ground shows the cold mark (in dark) of a disused path to a farm, now integrated in a plot of land (Odars, France), and invisible on a conventional image (right hand). The temperature scale on the left hand image indicates that the soil is $2^{\circ} \mathrm{C}$ cooler where was the path, probably because of the accumulation of wetness.
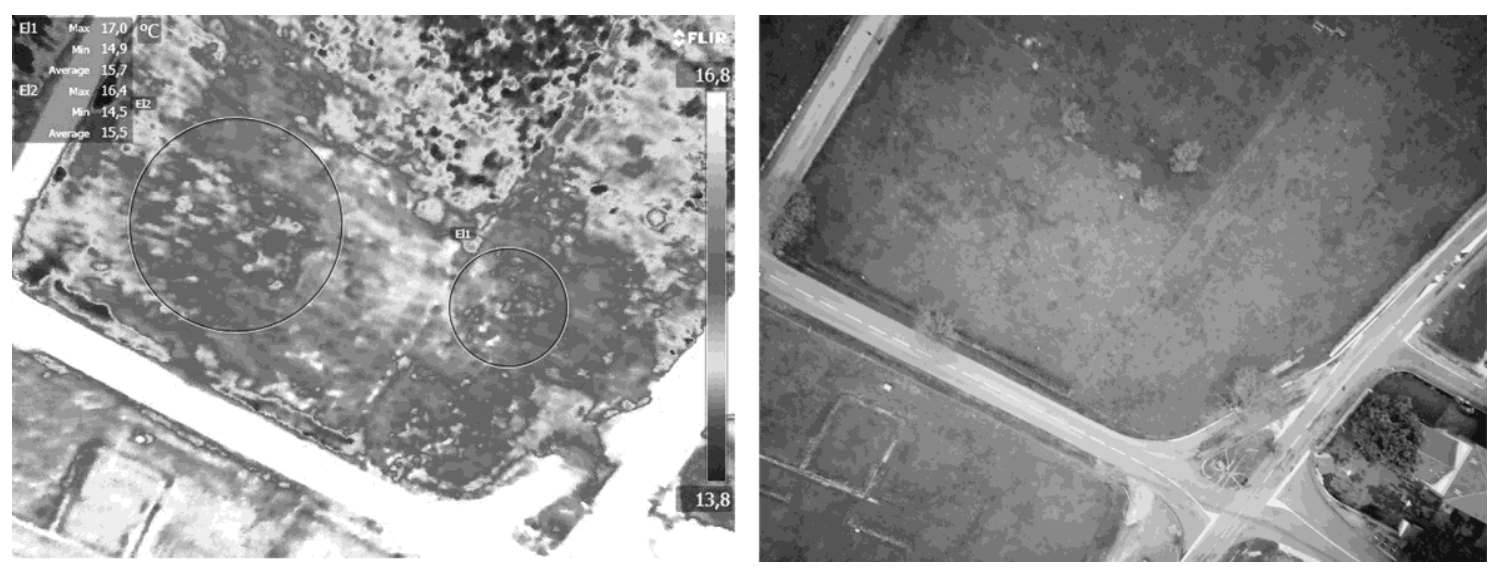

Figure 4 : On the left hand, the thermal image taken $100 \mathrm{~m}$ above the ground shows warm marks (in light). The circles show where these thermal anomalies are related to buried roman walls, which are invisible on the conventional image of the right hand (Saint-Bertrand-de-Comminges, France).
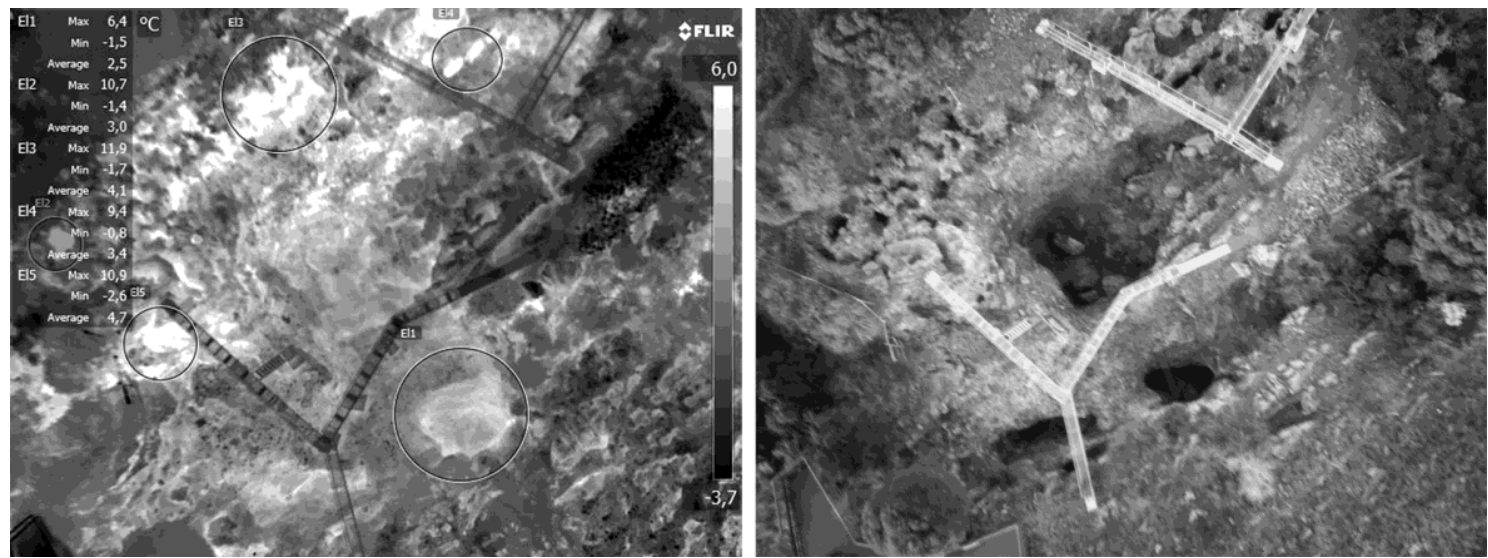

Figure 5 : On the left hand, the thermal image taken $50 \mathrm{~m}$ above the ground reveals warm marks (in light) indicating warm air outbreaks from underground caves (Sterkfontein cave, South Africa). The circles highlight the warmest anomalies interpreted as paths to hidden cavities. The conventional image (on the right hand) allows no distinction between the different holes. 